\title{
Addressing global sustainability challenges: a qualitative study on factors that promote transformative learning in engineering students
}

\author{
Douglas Tong Kum Tien ${ }^{1}$ (1) . Satesh Narayana Namasivayam ${ }^{1} \cdot$ Logendra Stanley Ponniah $^{2}$
}

Received: 5 December 2019 / Accepted: 30 June 2020 / Published online: 13 July 2020

(c) Springer Nature Switzerland AG 2020

\begin{abstract}
Engineers play crucial roles in helping overcome complex global challenges. These include challenges related to energy, environment, security, health, social and population growth issues which could threaten the sustainability of life on the planet. The complexity and scope of these challenges place ever increasing demands on the training of engineers. Embracing a more holistic approach that includes both informational and transformational aspects of learning may prove key in equipping engineers capable of leading the way in meeting and overcoming these challenges. This study focuses on the transformational aspect of learning. A qualitative study was conducted on participants from an Engineering School in Malaysia which had adopted the CDIO framework in its curriculum as well as provided its students with the opportunity of being voluntarily involved in the Grand Challenges Scholars Program. There were also ample opportunities for students to participate in extracurricular activities. The aim of this study was to identify the factors that promoted transformative learning in students. These factors were found to be the breaking out of comfort zones, having crucial learning experiences and in staying motivated throughout the process. A variety of subthemes clustered under each of these main themes or factors. The transformative learning outcomes enabled by these factors were found to be new and different ways of thinking, improved people and relational skills, made project management ability second nature and improved resilience. Such qualities would be useful in addressing global sustainability challenges and consistent with education for sustainable development and global citizenship.
\end{abstract}

Keywords Engineering education - Transformative learning - Sustainable development · Project-based learning · Qualitative study

\section{Introduction}

The challenges encountered by today's twenty-first century society are far more complex than that of any generation preceding it. It is also a matter of great concern that they continue to increase in their complexity unabated. These challenges encompass social, environmental, energy, health, security challenges along with the multitude of challenges associated with population growth.
The United Nations issued a list of 17 of sustainable development goals (UNSDG) [1, 2]. Among these are goals related to clean water and sanitation, affordable and clean energy, industry, innovation and infrastructure, sustainable cities and communities, responsible consumption and production, and climate action. Engineers have the potential to play vital roles in helping to achieve these goals and perhaps the other goals as well through technology and innovation.

Douglas Tong Kum Tien, DouglasKumTien.Tong@taylors.edu.my ${ }^{1}$ School of Engineering, Faculty of Innovation and Technology, Taylor's University, 1, Jalan Taylors, 47500 Subang Jaya, Selangor, Malaysia. ${ }^{2}$ School of Education, Faculty of Social Sciences and Leisure Management, 1, Jalan Taylors, 47500 Subang Jaya, Selangor, Malaysia. 
Consequently, the education of engineers is critical and of necessity adapt to deal with the challenging expectations on the knowledge, skills and mindsets of engineers. Current global efforts to address these demands include the Washington Accord Graduate Attributes [3, 4], the National Academy of Engineering's (NAE) Grand Challenge Scholars Program $[5,6]$ and the CDIO initiative $[7,8]$. It is worth noticing that these initiatives focus on the development of both hard and soft skills. The emphasis on non-technical competencies and soft skills is evident.

Even as early as 1918, a report entitled "A Study of Engineering Education" by Mann declared that "personal qualities such as common sense, integrity, resourcefulness, initiative, tact, thoroughness, accuracy, efficiency, and understanding of men are universally recognized as being no less necessary to a professional engineer than are technical knowledge and skill" [9, p. 106]. Although worded somewhat differently due to the language usage of the day, these personal qualities appear to mirror the soft skills that an engineer of today is required possess and as recommended by the various educational initiatives.

The fact that the engineering community is still faced with the same educational challenges a century later should underline how important they are while also suggesting a pressing need to better understand how to bring about the development of these qualities. The compelling question to the curious among engineering educators is not just about how to inform students better but it is also about how to transform students. In other words, learning should be both informative and transformative. The latter is less explored, especially in an engineering education context and therefore this inquiry was chosen to drive this study.

Alongside curricular activities, students in an engineering program may also voluntarily engage in extracurricular activities. It is expected that significant learning could also take place in a variety of informal learning situations. Therefore, the research question is, "What causes transformative learning to take place in an engineering education experience"? with the possibility that the causation factors may be drawn from both curricular and extracurricular activities and that a complete engineering education experience should seek to embrace both.

The aim of this study is to understand the factors that promote transformative learning in engineering students leading to the attainment of the desired qualities essential for addressing complex global challenges as underscored by the UNSDGs. Hence while this study is defined by education for sustainable development and global citizenship, it also supports all other UNSDGs where engineers play key roles.

SN Applied Sciences

\section{Literature review}

A brief review of theories that help explain the factors uncovered in the study is presented.

Transformative learning was introduced to the field of adult education by Mezirow through an article that he published in 1978 entitled 'Perspective Transformation' [10]. Mezirow's definition of transformative learning: "Transformative learning refers to the process by which we transform our taken-for granted frames of reference (meaning perspectives, habits of mind, mindsets) to make them more inclusive, discriminating, open, emotionally capable of change, and reflective so that they may generate beliefs and opinions that will prove more true or justified to guide action" [11, pp. 7-8].

Mezirow's perspective transformation begins with what he calls a disorienting dilemma that eventually leads to a change in either a meaning scheme or a meaning perspective. For Mezirow, this transformation occurs through a process of 10 stages [12-14]. While not all the 10 stages are necessary, it often follows some variation of these stages [11].

The desired transformation in this study should not be constrained by that defined by Mezirow. From a practical standpoint, what is sought cannot be limited only to the transformation of thought processes caused by the breaking of lesser and reforming of better mental perspectives. Rather it should expand to include all types of transformation that develops the entire person, and which would lead to the building of the capabilities needed to manage the twenty-first century's challenges. Nonetheless transformative learning theory can still provide useful insight.

Hoggan $[15,16]$ identified six categories of transformative learning outcomes. These are transformations in worldview, self, epistemology, ontology, behavior and capacity. Some of these transformations were observed in this study. Tien et al. [17] in evaluating the potential of applying transformative learning theory to engineering education consider Hoggan's metatheoretical approach to be well-suited for classifying the outcomes. Hoggan $[15,16]$ further identified the criteria of the depth, breath and the relative stability of change as conditions for transformative learning.

At present, there is a scarcity of transformative learning research focused on engineering education. A literature review by Tien et al. [17] found only six studies. Four were conference proceedings, one was a thesis and one was an online article. Even then two of them were misnamed as there was no application of transformative learning theory, while another focus on educators instead of on students. There were no journal papers 
regarding transformative learning theory in engineering education found. There is however a book on threshold concepts and transformational learning [18] which has two chapters devoted to engineering education. Nonetheless threshold concepts relate more to informational learning, i.e., gaining subject specific mastery than to non-technical competencies, while the aim and scope of this study is about understanding the development of non-technical competencies.

In the context of this study, transformative learning concerns the development of the qualities desired by the various engineering education initiatives, particularly those that relate to soft skills and non-technical competencies, with Hoggan's transformative learning outcomes and criteria serving as reference to define these transformations.

Another theory that can help explain the factors identified in this study would be the experiential learning theory. Experiential learning theory defines learning as "the process whereby knowledge is created through the transformation of experience. Knowledge results from the combination of grasping and transforming experience" $[19$, p. 41].

Kolb's idealized experiential learning theory (ELT) depicts a four-stage process of experiencing, reflecting, thinking and acting as being involved in the experiential learning $[19,20]$. These stages were identified as concrete experience, reflective observation, abstract conceptualization and active experimentation. In this idealized cycle, concrete experiences are reflected upon, abstract concepts are formed from these reflections and these concepts are actively tested in new situations. This cycle is depicted in Fig. 1.

The model portrays two dialectically related modes of grasping experience, i.e., concrete experience and abstract conceptualization, and two dialectically related modes of

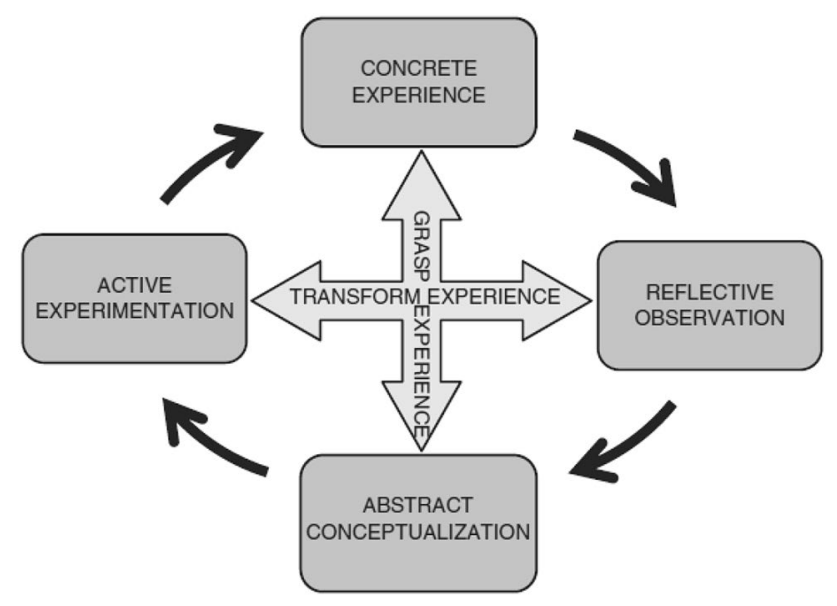

Fig. 1 Kolb's experiential learning theory [21] transforming experience, i.e., reflective observation and active experimentation [22].

Kolb's ELT has come under criticism over the years. Among these, the experience-reflect-learn pattern to experiential learning is considered as more of an ideology than a philosophy or theory of experiential learning [23]. However, Kolb's ELT is still the most well-known attempt at elaborating experiential learning and is useful as a starting point for understanding the phenomenon.

Motivation is crucial to learning including transformative learning. Motivation is associated with the learners' beliefs and values, with their goals and with social and cultural influences [24]. Learners' perceptions about their competence, their valuation of the task and their preexisting interest will all influence their motivation. Likewise, their goals will guide their decisions on whether to expend effort to achieve the desired outcomes. The types of goals can be broadly categorized as mastery goals where the objective is to increase competence and learning, and performance goals where learners desire to appear competent or to outperform others.

Social and cultural factors also influence motivation. These include social identity and stereotype threat. Social identity relates to the social roles that identifies one as a member of a certain group while stereotype threat is the unconscious concern that a stereotype about one's social group could be applied to oneself [24].

\section{Methodology}

Adopting an appropriate methodology is essential. In this study, the research interest lies in how the participants perceived their experiences in the engineering program. Hence the constructivist/interpretivist paradigm was considered the most appropriate. This paradigm assumes that meaning is not discovered as though it was inherent in an object but is constructed by human beings as they engage with the world that they are interpreting [25].

There was no attempt at the start in having any preconceived assumptions as to what the factors contributing to transformative learning might be nor was there any predetermined notion as to what changes the participants could have undergone. It was preferable for such information to emerge from the participants without any undue influence.

In view of this a qualitative study employing semi-structured interviews was used. This method allowed the findings to surface from the participants themselves through the meaning they made of their experiences. In contrast to this, a quantitative survey would limit the participants to choosing from among the factors predefined by the researcher and to merely assigning a quantitative rating 
to each of these factors in a survey form. This approach would inevitably exclude all factors not yet identified by the researcher. Furthermore, the level of understanding would not be as deep compared to qualitative research.

\subsection{Transferability}

Qualitative studies are constrained by their context and therefore the usefulness of a qualitative study is not dependent upon it being generalizable but rather on it being transferable. Transferability refers to the extent to which the results of one study can be transferred to or applied in other contexts or settings with other respondents [26]. Transferability is assisted through providing "thick description" of the participants, the context and the research process thus enabling the reader to assess if the findings are transferable to their own settings. The onus is on the readers to make their own transferability judgment while the researcher's responsibility is to provide a detailed description of the study's context to help the readers in this effort [26].

\subsection{Sampling}

Qualitative researchers recognize that some informants are more likely to provide the desired insight and understanding compared to others. For qualitative researchers, an improved understanding of complex human issues takes precedence over the generalizability of results [27]. In this qualitative study, an in-depth understanding of the phenomenon was desired rather than statistical generalizability therefore the sampling method employed was that of purposeful sampling. This method of sampling employs the purposeful selection of information rich cases from which the researcher can learn much about the issues of central importance [25]. Participants who were considered to have most likely undergone transformative learning were selected as they were expected to have the needed knowledge and experience to share with the researchers. It was expected that students who enthusiastically participated in both curricular and extracurricular activities and hence emulated the traits that the programme hoped to instill in them to be effective engineers were more likely to have experienced transformative learning during the programme.

In addition to knowledge and experience, the participants' availability and willingness to participate, along with their ability to communicate their experiences and opinions in an articulate, expressive, and reflective manner are equally important [28].

The criteria for the selection of interview participants are listed below.
1. Enthusiastic participation in curricular activities usually evidenced by an above average CGPA score.

2. Enthusiastic participation in extracurricular activities (ECA) evidenced by their roles and initiative displayed in ECA. It was anticipated that valuable learning may occur in a range of informal learning situations and that this would be especially true with transformative learning.

3. Unafraid to speak the truth.

4. Have good communication skills as this helps very much in interviewing.

The exclusion criteria would be those not considered to be in this category.

However, a couple of participants not in this category were also interviewed. Even in purposeful sampling, it is still possible to learn from extreme or deviant (outlier) cases. There is a type of purposeful sampling that does exactly this [28] although this was not the purpose of this study. The two outlier participants were participants no. 7 and no. 11. Data saturation already started to appear with participant no. 6 . These two participants were included mainly to yield additional insight. Apart from that the last two questions in the interview guide were as follow:

- What would be a least meaningful experience for you? (Factors that hinder transformative learning).

- Why is that?

These questions were intended to provide insight into the opposite of what was sought. They eventually served to confirm the validity of the findings as the factors that hindered transformative learning tended to be the opposite of those that facilitated it.

A description of each participant is provided in Table 1.

With regards to sample size, in qualitative studies it is recommended to sample to the point of saturation. That is, when no new information is forthcoming from the new sampled units the sampling can be terminated [25].

\subsection{Interview}

An interview was conducted whenever an identified interviewee agreed to participate. A consent form was emailed to each participant several days prior to the interview allowing them adequate time to digest the content. On the day of the interview, the form was reviewed with the participants and important points highlighted despite the interviewee having read the form prior to the interview. Only upon assurance that the purpose of the interview, the manner which it would be conducted, what was required of the interviewees and their rights as participants were fully understood, were they required to sign the form. 
Table 1 Information regarding the interview participants literature

\begin{tabular}{|c|c|c|c|c|c|}
\hline $\begin{array}{l}\text { Interview } \\
\text { partici- } \\
\text { pant }\end{array}$ & Program & Gender & $\begin{array}{l}\text { Eth- } \\
\text { nicity } \\
(\mathrm{M} / \mathrm{C} / \mathrm{I})\end{array}$ & Level of study at the point of interview & Reason for selection/remarks \\
\hline IP1 & ME & M & I & Completed semester 7 & Outspoken, displays leadership qualities, active in ECA \\
\hline IP2 & CE & $\mathrm{F}$ & $\mathrm{C}$ & Recent graduate & $\begin{array}{l}\text { Completed TGCSP. Showed initiative during TGCSP by } \\
\text { organizing a study trip to Japan }\end{array}$ \\
\hline IP3 & $\mathrm{EE}$ & M & $\mathrm{C}$ & Recent graduate & $\begin{array}{l}\text { Good academically, high Cumulative Grade Point Aver- } \\
\text { age (CGPA) score yet also very active in ECA }\end{array}$ \\
\hline IP4 & ME & M & C & Semester 6 & $\begin{array}{l}\text { Active in ECA, high CGPA score, President of Student } \\
\text { Council. Involved in TRC competition during Founda- } \\
\text { tion }\end{array}$ \\
\hline IP5 & ME & M & M & Semester 5 & Active in ECA. High CGPA score. Is articulate \\
\hline IP6 & ME & $\mathrm{F}$ & $\mathrm{C}$ & Recent graduate, employed & $\begin{array}{l}\text { Active in TRT, completed TGCSP, good CGPA and com- } \\
\text { municates well }\end{array}$ \\
\hline IP7 & $\mathrm{EE}$ & M & C & Completed semester 8 , awaiting results & $\begin{array}{l}\text { Recommended by another student due to a miscom- } \\
\text { munication. His interview was retained to serve as } \\
\text { insight into the challenges of non-transformation }\end{array}$ \\
\hline IP8 & CE & $\mathrm{F}$ & I & Recent graduate & $\begin{array}{l}\text { Outspoken and active in ECA. Displays leadership quali- } \\
\text { ties. The first president of TRC }\end{array}$ \\
\hline IP9 & ME & M & M & Recent graduate & Key leader of the TRT. Can communicate well \\
\hline IP10 & ME & M & $\mathrm{C}$ & Recent graduate, employed & $\begin{array}{l}\text { Completed TGCSP. One of the top students. Can expect } \\
\text { honesty from him }\end{array}$ \\
\hline IP11 & $\mathrm{EE}$ & M & C & $\begin{array}{l}\text { Recent graduate, applying for post- } \\
\text { graduate studies }\end{array}$ & $\begin{array}{l}\text { Good academically but no ECA. Deliberately selected to } \\
\text { have a participant with no ECA }\end{array}$ \\
\hline
\end{tabular}

There were no incidences of participants refusing to sign and wanting to withdraw. All of them were happy to share their experiences.

The interview was conducted in a semi-structured manner. In addition, field notes were taken by the researcher. These consisted of the researcher's impressions and observations during the interview. The transcription of the interview audio recordings was performed by a professional transcription service provider.

\subsection{Context}

Understanding the context is important for transferability. The following is a description of the context where the interview participants experienced their engineering education. The extracurricular activities are also described as they are considered to play a vital role in the transformative learning experiences of the participants.

The participants undertook their engineering undergraduate program at Taylor's University (TU) School of Engineering (SOE). TU is a relatively young private university being awarded full university status in 2010. With full university status TU awards its own undergraduate and postgraduate degrees. Prior to that TU was a tertiary institution that offered twinning programs where the degrees were awarded by foreign university partners.
SOE conducts three fully accredited four-year (eight semesters) B. Eng. (Hons) programs. These are in Chemical Engineering (CE), Mechanical Engineering (ME) and Electrical \& Electronic Engineering (EE). They are fully accredited by the Board of Engineers, Malaysia (BEM) through its Engineering Accreditation Council [29] and are therefore compliant with the Washington Accord since the BEM is a full signatory of the Accord [30]. SOE also offers a 1-year pre-university Foundation in Engineering program (FIE) that serves as a bridge between High School and the B. Eng. (Hons). However, students may also enroll into SOE's B. Eng. (Hons) from any other acceptable pre-university programs.

SOE has been a member of the CDIO Initiative since 2009 [31]. Consequently project-based learning (PjBL) is prominent in each of its program [32-34]. Group projects of a multidisciplinary nature are required in each semester from semesters $1-4$. This is followed by a twosemester monodisciplinary capstone group project spanning semesters 5 and 6 for $\mathrm{ME}$ and $\mathrm{EE}$, while for $\mathrm{CE}$ it spans semesters 7 and 8. Furthermore, if an interview participant had taken the FIE route, he or she would have had a further two semesters of group PjBL prior to entering the B. Eng. (Hons). All SOE students' PjBL outcomes are showcased in an end of semester event known as the Engineering Fair where external judges from academia and industry are invited to judge the 
students' artifacts [35]. In addition, there is also an individual Final Year Project that span semesters 7 and 8 applicable to all three of the B. Eng. (Hons) programs.

SOE is a member of the National Academy of Engineering's (NAE) Grand Challenges Scholars Program (GCSP) from 2015 onwards [36], having had the honor of being the first Engineering School outside of North America to be granted approval to conduct a GCSP. In SOE the GCSP is known as the Taylor's Grand Challenges Scholars Programme (TGCSP). The TGCSP was introduced to SOE's students in 2012 preceding the submission of the GCSP proposal to NAE and its subsequent approval $[37,38]$. Students may opt to join TGCSP voluntarily subject to passing a written application and an oral interview.

While attempting to meet the requirements of these education initiatives simultaneously may appear challenging, the program outcomes of SOE's B. Eng. (Hons) programs are intentionally and strategically aligned with goals of the Washington Accord Graduate Attributes, the CDIO syllabus and the GCSP in order to make this concurrent attainment achievable [39].

With regards to extracurricular activities (ECA), the Taylor's Racing Team (TRT) is a student-led initiative where the students design and build a race car to participate in various inter tertiary racing competitions in Malaysia and internationally [40]. In addition, the students are responsible to source sponsorship to finance the building of their car as well as their participation in competitions. The TRT began as a student-led initiative by the first cohort enrolled in SOE's B. Eng. programs. Membership in TRT is open to interested students from all three B. Eng. programs as well as to participants from other Schools are keen on this type of activity.

Apart from the TRT, there are other ECAs that the students may engage in. Among those undertaken by the interview participants included AISEC, the Student Council, and the Taylor's Robotics Club (TRC). AIESEC is a non-political, independent, not-for-profit international organization run by youth and recent graduates of institutions of higher education across the globe that serves as a global platform for young people to explore and develop their leadership potential [41]. An AIESEC chapter exist in TU. The Student Council is the representative body for all TU students responsible for Campus Welfare, Campus Relations and Campus Integration initiatives [42]. Student representatives are elected to the Council on a yearly basis. The TRC is an SOE initiative that was formed to encourage interest in robotics by the students and to participate in robotics competitions.

\subsection{Participants}

A total of 11 participants were interviewed. The majority comprised of the newly graduated as they had completed the entire program with their recent experience still fresh in their memory. Initially participants who were still undergoing the program were also selected but it appeared that the responses of the participants in later semesters seemed more complete, so it was decided to focus on those who had already completed the program. Table 1 describes the participants and the reason for their selection.

The participants were all Malaysians comprising of its three main ethnicities of Malay, Chinese and Indian. Seven of the participants were Chinese, two Malays and two Indians. This represented the approximate composition of Malaysian student ethnicity in SOE. Malaysians made up the majority of SOE's students while those of other nationalities were few and diverse hence it was decided to focus only on Malaysian students. Most of the participants were from ME as ME students made up the majority in SOE.

\subsection{Data analysis}

All interview transcripts received from the professional transcriber were compared against the interview's original audio recording. These were reread while recording was replayed to ascertain the accuracy of the transcription.

The transcripts were reread multiple times in the process of coding. Segments in the first interview transcript that contained relevant information and represented the smallest piece of information that can standalone were identified. These open codes were grouped into similar categories. This categorization of open codes into similar categories is known as axial coding [25]. The coding process was repeated for the second interview transcript which was examined for the presence of these same categories.

This process produced a master list of classification. Subsequent items were sorted into these categories. The initial master list was further revised and refined through information from succeeding data sets. Applying this method, the categories or themes that represented the factors promoting transformative learning gradually emerged. The analysis was discontinued upon attaining data saturation.

\subsection{Member check}

One of the constructs for ensuring the trustworthiness of a qualitative study is that of credibility. Credibility as a construct is concerned with the confidence that can be placed in the truth of the qualitative research findings [26]. One 
key strategy used to establish credibility is member check [43]. Member check requires that the themes and where relevant, any specific description of a related activity are taken back to the participants to determine whether the participants feel that these findings by the researcher were accurate [44]. Member check was performed by sending the data analysis section of this paper to all 11 interview participants. The participants had read and endorsed the accuracy of their interview responses and the accurate interpretation of their interview data.

\section{Transformative learning outcomes}

From the data analysis, the main areas of transformation perceived by the participants were in the improvement of their people and relational skills, in developing their project management skills, in changes in their way of thinking and increasing their resilience. Each of these outcomes are elaborated in the subsequent sections.

\subsection{People and relational skills}

Transformation in people and relational skills included leadership, working with people, handling difficult team members, understanding others better, overcoming shyness and effective communication. These can be associated with transformation in the participants' worldview, self and behavior based on Hoggan's transformative learning outcomes $[15,16]$. A sample of interview participants' responses is provided below.

IP2 was a project team leader who had to deal with several difficult team members as early as her foundation year in FIE and consequently managed to develop an emotional capacity to work with difficult people.

But what you hear from people "I think you're a very nice person, you never actually like argue with people" and stuff like that, but then, when I think back of myself, it's like I think maybe because of the tolerance I have developed during Foundation.-IP2

IP10 and IP1 managed to develop people skills in the area of motivation and in understanding another's perspective respectively, achieved through working in their group projects.

That's part of the leadership skills, and being persuasive is very important, and knowing who should get what task and keeping them interested, passionate, happy.-IP10

I have to understand different perspectives of the different people that we are working with, so it gave me a better more communicating style to learn or to communicate better with different people.-IP1

\subsection{Project management skills}

The specific project management skills which the interview participants developed included a structured approach to problem solving, time management skills, an attitude of preparedness for eventualities, resource planning and management skills, adopting a systematic approach and being attentive to details. These were primarily behavioral transformation $[15,16]$. A sample of the participants' responses is provided below.

It is apparent that participants have internalized good project management practices which they continue to apply into the present. For IP5, this is in his projects in the subsequent semesters while for IP10 this is at his work in his present place of employment.

Everything I do needs to be planned out well, so that everything can be done from A to Z. And let's say things don't work out, you should have back up plan to it, or should have you know, plan A, plan B, plan $C$. It just teaches me to be more prepared for things, makes me less naïve.-IP5

In project management you need ideas, you need time, a lot more time, you need to think about how to fabricate it. So, projects help a lot in that way.-IP10

Participants also developed an ability for structured problem solving. IP6 was reflecting on her initial exposure to project-based learning. In the second excerpt she reflected on the confidence she had gained from becoming well-acquainted with systematic problem formulation and solution through her experience working on complex open-ended group projects.

But because we were so used to that kind of situations, second semester was the same, nobody could help us, like into detail. So, we came up with the solution ourselves and after the third semester, it's kind of like okay, we need to figure it out ourselves....in the end we get used to the process.-IP6 Like some people when they get into a challenge then they get scared, but for us, okay, we have a challenge, can we do something, yeah. That kind of feeling, yes.-IP6

\subsection{Different ways of thinking}

Changes in ways of thinking were mainly changes in the participants' worldviews and in their epistemology. In this context, worldview refers to the way that the learner understands the world and how it works, while 
epistemology refers to the way the learner constructs and evaluates knowledge in their day-to-day living $[15,16]$. A sample of interview participants' responses is provided below.

Being exposed to a different country, culture and way of doing things was as eye-opening as it was transformative and it helped change a participant's worldview.

Because Kuwait has a very different climate to ours. It really broadened my world view to think that life is not just about what we have here (in Malaysia). They also believe they would have a good solution for their kind of thing and how can we make our solution to be applicable in their situation. It really opened my mind to consider other culture context, other geographical context.-IP6

IP11, a self-confessed nerd, had his way of thinking changed through a project-based module called Design and Innovation.

Initially, I was like some kind of nerd. When I'm doing a project, I usually just want to make the project perfect and then it's more like self-satisfaction. I don't care about the business value, that kind of stuff, but after I studied the subject of innovation, it changed my values because I switched my focus toward not the product itself but to the overall project including how to present it, and how to attract people's attention during presentation.-IP11

Initially I was more technical orientated doing project. After that, I shifted to become more business value orientated.-IP11

As IP9's response indicated, changes in perspectives can also come about through close interaction with others who have different perspectives from theirs.

Also, rather than just having engineering-focused friends, I had friends from business school, mass comm and they have like different perspectives and all, and you get to learn actually more about the world, rather than just have an enclosed engineering group which have kind of one perspective.-IP9

\subsection{Increased resilience}

Another transformative outcome observed was that of increased resilience. This attribute included staying calm in a crisis, having a strong work ethic, not quitting, and coping with adversities and failures. A sample of the participants' responses is provided below.

Crisis management was an attribute that IP4 attained through his projects and through his ECA participation.
This attribute once developed was still applicable for him in other contexts as he narrates below.

So, one thing that really changed me is crisis management. So even if let's say I'm taken out of the university, whenever I see a crisis let's say at home, my mom is frantic, my grandma is panicking, my father is being angry because everyone is panicking, I always act normally. I'm the only one that's calm at home trying to manage everyone, because of crisis management.-IP4

Other attributes inculcated through project-based experiences included adapting to adversity and not quitting when things got tough as shown by the responses below.

My ability to adapt to adversity, that's second oneIP1

I think the most valuable thing that I learnt from that is that it's not the information that you get, it's actually learning how to cope with your colleagues and your friends. And then, making sure that the projects are properly executed as planned or not as planned, yeah. Making it... never quitting until it gets into the end of the job-IP9

Transformation can also happen through assimilating the ethics and cultural norms of the group that one is a part of. In the excerpt below, IP9 reflected on how he was changed by the work ethic of his seniors in the TRT who had created a culture of hard work in the TRT team.

I just want to learn more of Formula 1 cars, just try to get as much skills as I can. And my seniors are quite good, very well-behaved people, very competitive. So, it's the right culture basically. Just the right culture for me. So, it tends to stick until my final semester because I love it so much and I learn a lot of skills. Basically, I think the most that change in me is the work ethic.-IP9

\section{Factors that promote transformative learning}

Three overarching themes emerged from the analysis of the interview data. They were the breaking out of comfort zones, having crucial learning experiences and in staying motivated throughout the process of transformation. Within these three themes comprised a variety of subthemes. These themes and their subthemes represented the factors that promoted transformative learning experienced by the interview participants. Each of these themes are elaborated in the subsequent sections. 


\subsection{Breaking out of comfort zones}

The first factor to emerge is the breaking out of comfort zones. The Cambridge dictionary defines a comfort zone as "a situation in which you feel comfortable and in which your ability and determination are not being tested" [45]. All human beings have their comfort zones. In order to grow, breaking out of one's comfort zone is often necessary.

In transformative learning, the breaking out of comfort zones corresponded closely to that of encountering a disorienting dilemma, with this being the first stage of Mezirow's transformative learning theory [10-14]. While Mezirow tended to associate disorienting dilemmas more with rational processes, however in the context of this study comfort zones were most often encountered in the emotional realm.

The data analysis revealed that breaking out of comfort zones is one of the factors that facilitated transformative learning. The subthemes included comfort zones related to dealing with difficult people, in making cold calls, in project related challenges, difficult tasks, critical situations, challenging environments, leading and public speaking. A sample of participants' responses with regards to coming out of their comfort zones and how that experience changed them is provided below.

IP1 overcame his shyness with regards to his task of contacting sponsors for exchange programs for AISEC after many attempts. He eventually managed to secure some personal appointments, overcame his shyness and was grateful for the experience.

Like I said I was a very shy person, having my first cold call and I was very scared....... I was so scared, so nervous until that fella was so fed up of me, he started scolding me on the phone". But eventually "...I manage to secure a few personal appointments to meet them, like a few amazing people honestly, different fields and so on, and seal the deal myself.-IP1

IP2 shared about her discomfort in not being able to control circumstances so that having to come out of her comfort zone was a matter of necessity for her.

The special thing about group project is you can't do it on your own. So, when you can't control everything on your own, it's time for you to actually step out of your comfort zone to adjust everything and make it to the best like how you can make it because you need to work with people.-IP2

IP3 discussed his personal challenges in leading which required him coming out of his comfort zone.
Yes, because I'm not really into leading but I used to have a lot of leadership positions before but it's not what I like to do. But I still to push myself through the comfort zone to lead.-IP3

IP6 shared about her discomfort of encountering an openended challenge for the first time in her project-based learning experience. (She eventually overcame this fear and became comfortable in dealing with complex challenges as evidenced in her response in the Project Management Skills section).

And then we realized he's not going to give us the answer, it was scary, I remember because we felt like we couldn't accomplish the task.-IP6

As can be observed from these sample responses, the emotional element is quite noticeable. Comfort is often affected at the emotional level before and more than at the cognitive level. Hence venturing out of one's comfort zone would require an ability to cope with one's emotions especially at the initial stages of the encounter. This would need to happen alongside the disorienting dilemma of meaning schemes and meaning perspectives mentioned in Mezirow's transformative learning theory.

\subsection{Crucial learning experiences}

The second factor to emerge is that of having crucial learning experiences which were experiential in nature. To transform, learning that is experiential can be effective in a way that theoretical learning by itself is unable. This theme diverges from that of breaking out of comfort zones in that experiences which do not compel a participant out of their comfort zone can still be transformative with regards to the outcomes sought in this study.

Subthemes of this category of crucial learning experiences include fully experiencing a real project, in applying knowledge gained to real projects, working with people, stepping out of disciplinary boundaries and experiencing different cultures and work ethic. These subtheme experiences need not always be personal but could also be secondary experiences such as learning from others' experiences. A sample of participants' responses is provided below.

IP3 and IP5 opined that there are aspects of learning that must be experiential in order to be effective. These experiences can be considered transformative in the sense that the participants are significantly affected and have the potential to produce outcomes in self and behavior $[15,16]$.

I actually find it helpful in the sense that I get to be involved in a lot of projects. I learn how to manage in a group, how to manage my project, the time 
management and all those. There're some skills I think you can't learn from a textbook but you have to learn it from experience.-IP3

Because if we just learn it by theory, by just reading it, you don't get to practice it. It only gets instilled once I tried applying it on my own, and not when I'm... I mean not during class or not during the tutorial but using what I learnt in class, when I'm doing something on my own which is the project.-IP5

IP6 and IP9 pondered about the need for repetition until a difficult experience becomes natural to them. This can also be considered transformative within the context the transformations sought in this study.

And then having bits where we can put our learning into actual practical examples, it's actually very helpful...not just one time to do it, but like over and over again, and came like second nature.-IP6 I think the main reason because you have done it like, I think I clocked out 1200 calls in AIESEC; so, you get used to it. Once you get used to it, it's pretty easy to do, yeah, just that first few steps (was hard)._IP9

IP9 reflected on his community service experience of teaching underprivileged children to build an engineering artifact which humbled him and changed his perspective. This proved to be a crucial learning experience for him resulting in changes to worldview and self.

' 6 people trying to make a bubble machine work; it took like, 2 weeks to do it and the kids took like, 2 days to do it. It puts into perspective that you shouldn't over think stuff and don't underestimate that even small kids could be very smart. That tone down my ego a bit... it's a humbling experience basically... having that is a great because at first, all of us think that, okay, this is CSR module, we shouldn't focus so much on it. But it turns out to be the most rewarding in terms of self.-IP9

IP10 narrated his experience about a study trip to Japan as part of his TGCSP multicultural competency requirement. This crucial experience made a huge impact on his way of thinking.

It's a totally different culture than what we are used to. We visit their schools, universities, we found out it was very different. And these Japanese, they focus a lot on renewable energy, in Malaysia we don't... we don't see it. It makes you think about why can't we do this back home?-IP10

IP8 shared about her internship with an air conditioner manufacturer at the end of her third year of study and the crucial role that her prior project-based learning experiences have had on her confidence.

I was just assigned a task to dissemble or assemble the parts, I was like okay, I will do it. Then you know, when they saw me, I was able to carry it and do it by myself, and not asking for help. Their first impression, a girl is doing mechanical work. Then their mind gets blown. Then they see a chemical engineering student knows, you know, all this. I would say, in truth, chemical engineering didn't teach me this. It was the projects that taught me this.-IP8

At times, the experiences need not be personal but could be vicarious. Secondary experiences could still be effective [46] and the responses below bore this out.

I came to the school, not only to learn the knowledge, the book knowledge. The book knowledge is easy, right, you can just read the slide and then you learn by yourself at home. What I want to learn is the experience or knowledge that is already experienced by those lecturers in the past. Because they have experience, so you can ask about their experience or their opinions, about how they think about some stuff or future, that kind of stuff.-IP11

Experience wise...it was really connecting us to the outside world, especially we were meeting people who are in the industry. Our lecturers would bring them to give us talks. -IP8

Crucial learning experiences are beneficial for transformation. These experiences may be practical firsthand experiences, or they may be the experience of being exposed to different people and new environments, or they may even be secondary experiences shared with them by those whom they esteem.

Theoretical classroom learning by itself is inadequate for the type of transformation sought in this study. These transformations relate to the soft skills components desired by the various engineering education initiatives and which are very similar with the personal qualities mentioned in the Mann Report [9]. However, this should in no way imply that classroom learning is unimportant as engineers still need to be fully equipped with the necessary theoretical and technical knowledge. Even so their classroom learning could be judiciously supplemented by a variety of crucial learning experiences.

\subsection{Staying motivated}

The third factor to emerge is that of staying motivated throughout the process of transformation. This is to allow for the process to be completed. Transformation is not always easy. Hence the motivation to break out of one's 
comfort zone or to undertake a new or challenging experience and then to see that process through to the end requires considerable motivation. The nature of this motivation may be either intrinsic or extrinsic. Both appeared in the data, however intrinsic motivation was more frequently observed.

Associated subthemes included the motivation to learn, motivated by personal goals, motivated to improve, motivated by support from others, motivated by the challenge presented, motivated to discover one's capacity, motivated to by the opportunity offered to them, motivated by competition, by grades and even by the fear of failing and in coming last in a competition. The sources of motivation among the participants were quite varied. A sample of participants' responses is provided below.

IP9 was motivated by a personal goal to develop "sale skills" and by a preexisting interest in automotive racing that became a passionate obsession. This form of motivation would be considered as intrinsic motivation while the goals sought considered as mastery goals, i.e., goals related to increasing one's competence and understanding.

So, the reason why I joined AIESEC was because I know that I have zero sale skills and I want to build on it-IP9

In terms of TRT, I do it because of my goal, I want to be in the Formula 1 team.-IP9

For IP4, his valuation of the benefits that an opportunity offered him was the basis of his motivation.

I would see what are the benefits that I could get from it, if the benefits are me getting a new skill, and meeting more people or getting to, get more knowledge, and the only disadvantage is me sacrificing some time, then I will go straight into it. But if let's say there is nothing to gain from it and only me wasting my time, then I wouldn't.-IP4

IP1 was intrinsically motivated by a personal goal and it was his intrinsic motivation that helped him persist in the face of adversity which eventually resulted transformation.

So, this is not for me I thought, but something inside me told that if I were to give up at the time I may not, I will stay the same guy, I may not improve.-IP1

IP6 in recalling her first couple of project-based learning experiences confessed that her primary motivation at the time was not to be shamed. This may be considered as a form of performance goal motivation, i.e., the desire to appear competent or to outperform others. This form of motivation may still serve its purpose but is not usually considered as robust as mastery goals. Nonetheless in Asian cultures, performance goals are common and they tend not be perceived as negatively as in Western cultures [47].

So, what motivated us is not to be shamed, that we cannot even cross our obstacles, but maybe there was competition to it, so that was the reason why. Second semester was also the same, because in engineering fair, we don't want to end up the last team, so, we had to do the project well.-IP6

IP8 was inspired to undertake all manner of ECA because of the example she saw in students who were senior to her who were female like herself. This helped to create a positive social identity and broke any stereotype threat which may have worked against her motivation [24]. Having role models to emulate can serve as a source of motivation.

I would say when I was studying with seniors like F, she was very good. I was so like, she can do it and there's always this image where you know, girls are only good at one thing, so I said $M$ was very good also. So, when you are always surrounded by people like this, I find it's okay.-IP8

I don't actually look at my friends who are not making an effort. I have friends who throughout the four years were barely involved in any extra-curriculum, because they feel like classes are already overwhelming, projects are overwhelming, they don't have the time. But then I also can see those who already have this and they are doing beyond. Well, let's join them.-IP8

Having the support of others is an important element for staying motivated. Support lightens the load by providing emotional energy.

In some cases, I can see that support from your friends, people you hang out with actually contributes a lot. We motivate each other. It's that mutual support with your peers and then you notice this if you work harder together.-IP6

Support was noticeably absent from the experience of IP7, being the only participant interviewed who seemed to register no transformation.

Awkward but I just cope with it. Last year was actually quite tough but I just cope with it._IP7

IP7's comment relates to his experience in his team after falling out with a team member and in retaliation that team member turned the entire team against him. Unfortunately, he was from the program which had a very small enrollment. His cohort consisted of less than ten students, so he had to continue in the same team. 
He is still coming to terms with his experience and it may yet prove transformative for him at some future time.

Staying motivated is crucial to avoid the transformative process from being aborted prior to its completion. Transformation is a process and similar with all processes it requires time. It does not happen in an instant nor does it happen without effort expended. This effort may involve having to pursue opportunities, overcoming adversities, dealing with emotional discomfort, working with difficult people, not quitting, and so on. The effort may be mental or emotional or likely to be both, but in the process something transformational occurs. Therefore, staying motivated until the process is complete is essential. Motivation is akin to the foundations that support the twin pillars of breaking out of comfort zones and having crucial learning experiences.

\section{Discussion}

From the data analyzed, it is important that the students be provided with ample opportunity to experience new and challenging activities. From a curricular perspective, the most effective means to achieve this is through project-based learning. The projects should be designed for experiential learning. If such projects are offered every semester, the students will be able to keep improving and developing the necessary capabilities through repeating the Kolb experiential learning cycle [19-22] again and again, improving through each cycle.

Projects may intentionally and unintentionally provide experiences that challenge the students' comfort zones such as facing a complex challenge for the first time with minimal guidance or dealing with difficult team members. Students' comforts zones are challenged both rationally and emotionally. Leaving a comfort zone is akin to experiencing a disorienting dilemma which has the proven potential for transformative learning [10-14]. In some case motivational support may be necessary however how to provide this may require further study.

From the experience of one of the authors, when he visits the students at their industrial attachment and queries the industrial supervisor regarding the students' performance, he frequently receives positive feedback. Often the industrial supervisor would regard the intern as among the best and this can be attributed primarily to the regular project-based learning experiences which the student has undergone prior to the industrial attachment.

In addition, there needs to be an ecosystem whereby students can freely choose to develop themselves in line with their personal goals and aspirations. This can be provided through interesting, challenging and diverse ECA. The ECA may be engineering related such as a racing team or a robotics club. They may also be non-engineering related such as AISEC or the Student Council. The key is to make these opportunities available. This is because informal learning experiences often possess potent transformative learning potential.

A program such as TGCSP is also helpful. It specifies key competencies for the students to achieve and hence motivates the students to achieve them. This is especially true with regards to the multicultural competency. As the interview data revealed, having an experience in a different country and culture was a transformative experience.

The visual model shown in Fig. 2 may be helpful to illustrate the findings. Transformative learning in the context of engineering education at $\mathrm{SOE}$ is represented by a roof. The roof symbolizes the apex of what we want to achieve. The roof rests on two pillars. These pillars signify crucial learning experiences and the breaking out of comfort zones. For these two factors to have the intended effect the students need to stay motivated throughout the entire process of transformation. Hence staying motivated which is the third factor is symbolized by the underground foundations on which these two pillars receive support. The entire structure consisting of roof, pillars and foundation is firmly embedded into the ground. The ground therefore represents an educational ecosystem conducive to fostering transformative learning. The potential for transformative learning is augmented if a suitable ecosystem is provided.

\section{Conclusion}

A qualitative study was conducted with the intention of identifying and understanding the factors that promoted transformative learning in engineering undergraduates. This study was carried out at a Malaysian private institution

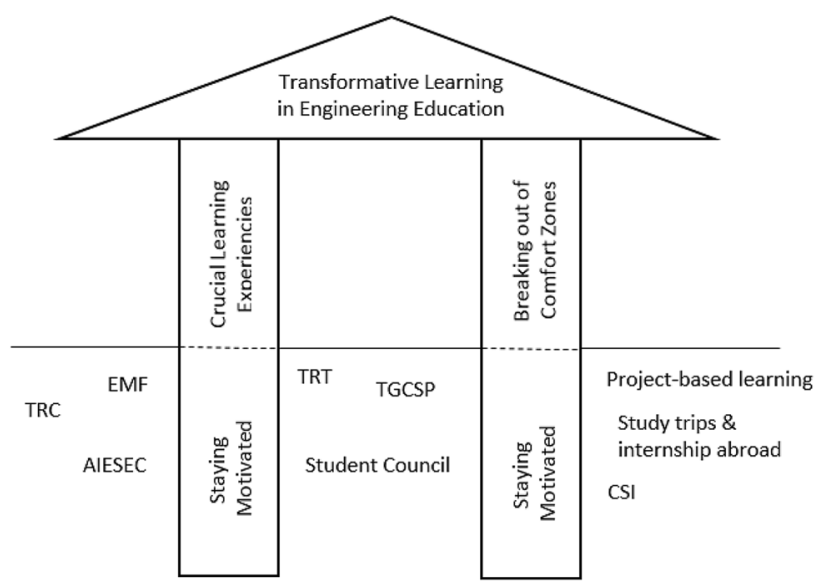

Fig. 2 A visual model of transformative learning in an engineering education context 
of higher learning which housed a School of Engineering. The student composition at the School of Engineering consisted of its three main ethnicities and interview participants were selected from among them. The factors that promoted transformative learning were identified as the breaking out of comfort zones, having crucial learning experiences and staying motivated throughout the process of transformation. These factors were the main themes that emerged from coding the interview data and congregating under each of these themes were a variety of subthemes.

An educational ecosystem that embraces project-based learning and which can provide ample opportunities for students to participate in extracurricular activities was found to be conducive in supporting transformative learning. The transformative outcomes included enhanced people and relational skills, with project management skills becoming second nature, in discovering and adopting different ways of thinking and in increasing resilience. These are outcomes that align with the soft skills desired by the various engineering education initiatives because they contribute toward equipping engineers who not only possess the hard skills but also the soft skills and nontechnical competencies vitally needed to lead the way in confronting today's and tomorrow's global sustainability challenges which are underscored by the UNSDGs.

Acknowledgements This study was funded by the Taylor's Research Grant Scheme, Project Code:TRGS/ERFS/1/2017/SOE/025.

\section{Compliance with ethical standards}

Conflict of interest The authors declare that they have no conflict of interest.

\section{References}

1. United Nations Development Programme (nd) Sustainable development goals. http://www.undp.org/content/dam/ undp/library/corporate/brochure/SDGs_Booklet_Web_En.pdf. Accessed 10 Apr 2019

2. United Nations (nd) Transforming our world: The 2030 agenda for sustainable development. https://sustainabledevelopme nt.un.org/content/documents/21252030\%20Agenda\%20for $\% 20$ Sustainable\%20Development\%20web.pdf. Accessed 10 Apr 2019

3. International Engineering Alliance (2013) Graduate attributes and professional competencies. http://www.ieagreements.org/ assets/Uploads/Documents/Policy/Graduate-Attributes-andProfessional-Competencies. Accessed 10 Apr 2019

4. International Engineering Alliance (nd) 25 years of the Washington Accord. http://www.ieagreements.org/assets/Uploads/ Documents/History/25YearsWashingtonAccord-A5bookletFINAL.pdf. Accessed 10 Apr 2019

5. Katsouleas T, Miller R, Yortsos Y (2013) The NAE grand challenge scholars program. Bridge-Natl Acad Eng 43:53-56
6. National Academy of Engineering (nd) NAE grand challenge scholars program. http://www.engineeringchallenges.org/ GrandChallengeScholarsProgram.aspx. Accessed 10 Apr 2019

7. CDIO (nd) About CDIO. http://www.cdio.org/about

8. Crawley EF, Malmqvist J, Lucas WA, Brodeur DR (2011) The CDIO syllabus v2.0. An updated statement of goals for engineering education. In Conference Proceedings of the 7th International CDIO Conference. CDIO Conference, Copenhagen

9. Mann CR (1918) A study of engineering education. The Carnegie Foundation for the Advancement of Teaching, New York, p 106

10. Mezirow J (1978) Perspective transformation. Adult Educ $Q$ 28:100-110. https://doi.org/10.1177/074171367802800202

11. Mezirow J (2000) Learning to think like an adult. Core concepts of transformation theory. In: Mezirow J (ed) Learning as transformation. Critical perspectives of a theory in progress. Jossey-Bass, San Francisco, pp 3-33

12. Mezirow J (1981) A critical theory of adult learning and education. Adult Educ Q 32:3-24. https://doi.org/10.1177/0741713681 03200101

13. Mezirow J (2009) An overview of transformative learning. In: Illeris K (ed) Contemporary theories of learning. Routledge, London, pp 90-105

14. Mezirow J (2009) Transformative learning theory. In: Mezirow J, Taylor EW (eds) Transformative learning in practice. Insights from community, workplace, and higher education. Jossey-Bass, San Francisco, pp 18-32

15. Hoggan CD (2016) A typology of transformation: Reviewing the transformative learning literature. Stud Educ Adults 48:65-82. https://doi.org/10.1080/02660830.2016.1155849

16. Hoggan CD (2016) Transformative learning as a metatheory: definition, criteria, and typology. Adult Educ Q 66:57-75. https ://doi.org/10.1177/0741713615611216

17. Tien DTK, Namasivayam SN, Ponniah LS (2019) A review of transformative learning theory with regards to its potential application in engineering education. AIP Conf Proc. https:// doi.org/10.1063/1.5121003

18. Meyer JHF, Land R, Baillie C (2010) Threshold concepts and transformational learning. Sense Publishers, Rotterdam

19. Kolb DA (1984) Experiential learning: experience as the source of learning and development. Prentice Hall, Englewood Cliffs

20. Kolb AY, Kolb DA (2005) Learning styles and learning spaces: enhancing experiential learning in higher education. Acad Manag Learn Educ 4:193-212. https://doi.org/10.5465/ AMLE.2005.17268566

21. Kolb AY, Kolb DA (2009) The learning way: meta-cognitive aspects of experiential learning. Simul Gam 40:297-327. https ://doi.org/10.1177/1046878108325713

22. Kolb DA, Boyatzis RE, Mainemelis C (2001) Experiential learning theory: previous research and new directions. In: Sternberg RJ, Zhang LF (eds) Perspectives on thinking, learning and cognitive styles. Lawrence Erlbaum Associates, Mahwah, pp 227-247

23. Seaman J (2008) Experience, reflect, critique: the end of the "learning cycles" era. J Exp Educ 31:3-18. https://doi. org/10.1177/105382590803100103

24. National Academies of Sciences, Engineering, and Medicine (2018) How people learn II: learners, contexts, and cultures. The National Academies Press, Washington

25. Merriam SB (2009) Qualitative research: a guide to design and implementation. Jossey-Bass, San Francisco

26. Korstjens I, Moser A (2018) Series: practical guidance to qualitative research. Part 4: trustworthiness and publishing. Eur J Gen Pract 24:120-124. https://doi.org/10.1080/13814 788.2017.1375092

27. Marshall NM (1996) Sampling for qualitative research. Fam Pract 13:522-525. https://doi.org/10.1093/fampra/13.6.522 
28. Palinkas PA, Horwitz SM, Green PA, Wisdom JP, Duan N, Hoagwood K (2015) Purposeful sampling for qualitative data collection and analysis in mixed method implementation research. Admin Policy Mental Health Mental Health Serv Res 42:533-544. https://doi.org/10.1007/s10488-013-0528-y

29. Engineering Accreditation Council Malaysia (nd) List of accredited engineering programme (Malaysia). http://www.eac.org. my/web/list_accredited.html. Accessed 10 Apr 2019

30. International Engineering Alliance (nd) Washington Accord signatories. http://www.ieagreements.org/accords/washington/ signatories/. Accessed 10 Apr 2019

31. CDIO (nd) CDIO members. http://www.cdio.org/cdio-membe rs?page $=10$. Accessed 10 Apr 2019

32. Chung ECY (2019) The design spine: the core design modules behind Taylor's School of Engineering project-based learning. In: Mahdiraji GA, Chung ECY, Namasivayam SN, Fouladi MH (eds) Engineering grand challenges in scholar programs. Springer, Singapore, pp 17-31

33. Ng KY, Chung ECY (2019) Project-based learning and why it works: a student perspective. In: Mahdiraji GA, Chung ECY, Namasivayam SN, Fouladi MH (eds) Engineering grand challenges in scholar programs. Springer, Singapore, pp 33-37

34. Al-Atabi M, Chung E, Namasivayam S, Al-Obaidi ASM, Shamel MM (2013) A blueprint for an integrated project based learning framework in engineering education: a case study at Taylor's University. J Eng Sci Technol 8:8-18

35. Ng KY, Chung ECY (2019) Engineering fair: going beyond the classroom. In: Mahdiraji GA, Chung ECY, Namasivayam SN, Fouladi $\mathrm{MH}$ (eds) Engineering grand challenges in scholar programs. Springer, Singapore, pp 45-54

36. NAE Grand Challenges for Engineering (nd) Schools with approved GSC programs. http://www.engineeringchallenge s.org/15784.aspx?id=15784. Accessed 10 Apr 2019

37. Tien DTK, Namasivayam SN, Eh Noum SE (2019) The Taylor's grand challenges scholars program: preparing for tomorrow's solutions by engaging with students today. In: Mahdiraji GA, Chung ECY, Namasivayam SN, Fouladi MH (eds) Engineering grand challenges in scholar programs. Springer, Singapore, pp $1-16$
38. Al-Atabi M, Tien DTK (2013) A blueprint for implementing grand challenge scholars' programme: a case study of Taylor's University. J Eng Sci Technol 8:80-86

39. Al-Atabi M, Namasivayam S, Chong $\mathrm{CH}$, Choong F, Hosseini $\mathrm{M}$ (2013) A holistic approach to develop engineering programme outcomes: a case study of Taylor's University. J Eng Sci Technol 8:19-30

40. Taylor's University (nd) Taylor's racing team. https://university 2.taylors.edu.my/engineering/taylors-racing-team. Accessed 10 Apr 2019

41. AISEC in Malaysia (nd) Who are we? https://www.aiesec.my/ about-us/. Accessed 10 Apr 2019

42. Taylor's University (nd) Student council. https://university2.taylo rs.edu.my/campus-life/student-experience/student-council. Accessed 10 Apr 2019

43. Shenton AK (2004) Strategies for ensuring trustworthiness in qualitative research projects. Educ Inf 22:63-75. https://doi. org/10.3233/EFI-2004-22201

44. Creswell JW (2014) Research design: qualitative, quantitative, and mixed methods approaches, 4th edn. Sage, Los Angeles

45. Cambridge Dictionary (nd) Meaning of comfort zone in English. https://dictionary.cambridge.org/dictionary/english/comfortzone. Accessed 10 Apr 2019

46. Bergsteiner $\mathrm{H}$, Avery GC (2014) The twin-cycle experiential learning model: reconceptualising Kolb's theory. Stud Contin Educ 36:257-274. https://doi.org/10.1080/0158037X.2014.904782

47. King RB, Mclnerney DM (2014) Culture's consequences on student motivation: capturing cross-cultural universality and variability through personal investment theory. Educ Psychol 49:175-198. https://doi.org/10.1080/00461520.2014.926813

Publisher's Note Springer Nature remains neutral with regard to jurisdictional claims in published maps and institutional affiliations. 